\title{
Увеличение числа органов международного правосудия и их влияние на систему международного права
}

\author{
Смбатян А.C. ${ }^{*}$
}

В последней декаде XX века произошло разительное увеличение числа органов международного правосудия. В частности, были созданы: Орган по разрешению споров Всемирной торговой организации ${ }^{1}$, Международный трибунал по морскому праву ${ }^{2}$, процедура разрешения споров в рамках Североамериканской зоны свободной торговли ${ }^{3}$, Международные уголовные трибуналы по бывшей Югославии ${ }^{4}$ и Руанде 5 , процедура разрешения споров в рамках МЕРКОСУР 6 и т.д.

Понятие «органы международного правосудия» включает судебные, квазисудебные и арбитражные органы, в функции которых входит урегулирование международных споров: различные суды, трибуналы, комиссии, центры, палаты, арбитражи и т.д. Среди органов международного правосудия особое место занимают органы международного судопроизводства. Органами международного судопроизводства являются органы, отвечающие следующим критериям.

\footnotetext{
* Смбатян Анаит Сергеевна - к.ю.н., преподаватель кафедры публичного права Всероссийской академии внешней торговли, заместитель директора департамента договорных и международных корпоративных дел ОАО «Мечел».

1 См.: Договоренность о правилах и процедурах, регулирующих разрешение споров, которое включено в приложение 2 к Марракешскому соглашению, подписанному в апреле 1994 г. и вступившему в силу 1 января 1995 г.

2 См.: Конвенция ООН по морскому праву 1982 г. вступила в силу 19 ноября 1994 г.

3 См.: Соглашение о создании Североамериканской зоны свободной торговли 1992 г. вступило в силу 1 января 1994 г.

4 См.: Резолюция Совета Безопасности ООН № 827 (1993) о создании Международного трибунала для судебного преследования лиц, ответственных за серьезные нарушения международного гуманитарного права, совершенные на территории бывшей Югославии.

5 См.: Резолюция Совета Безопасности ООН 955 (1994) о создании Международного трибунала с целью судебного преследования лиц, ответственных за геноцид и другие серьезные нарушения международного гуманитарного права, совершенные на территории Руанды.

6 См.: Договор о создании Общего рынка между Аргентиной, Бразилией, Парагваем и Уругваем 1991 г., вступивший в силу 29 ноября 1991 г. (Treaty of Asunción).
} 
Во-первых, такие органы должны быть постоянно действующими - их создание не должно зависеть от воли спорящих сторон. Этот критерий отсекает арбитражи ad hoc.

Во-вторых, органы международного судопроизводства должны быть учреждены на основании международного договора либо иного международно-правового акта.

В-третьих, споры в рамках органов международного судопроизводства должны разрешаться на основании международного права и в соответствии с процедурой (регламентом), не зависящей от воли спорящих сторон.

В-четвертых, принятое решение должно обладать обязательной юридической силой. При этом имеется в виду только решение, принятое по результатам рассмотрения споров. Здесь речь не идет о том, что регламенты некоторых органов международного судопроизводства предусматривают отдельные процедуры по принудительному выполнению таких решений либо по получению истцом разрешения на применение санкций в отношении ответчика, не выполняющего принятое решение. Например, в Организации Объединенных Наций таким органом является Совет Безопасности ${ }^{7}$, во Всемирной торговой организации - Орган по разрешению споров 8 .

В-пятых, назначение судей (арбитров) не должно зависеть от воли спорящих сторон, они должны осуществлять свои полномочия в течение фиксированного периода времени и получать заработную плату. Выполнение указанных требований обеспечивает независимость судей.

Далее, одной из спорящих сторон должно быть государство либо международная организация. Этот критерий отсекает органы международного правосудия, рассматривающие споры между частными лицами.

И, наконец, критериям органа международного судопроизводства в рассматриваемом контексте соответствуют органы с универсальной юрисдикцией, а также органы, рассматривающие споры в определенных областях, но правом доступа в которые обладают государства, вне зависимости от своего географического расположения.

Примечательно, что наиболее значимые в истории международных отношений органы судопроизводства, как правило, создавались

\footnotetext{
7 Статья 94 Устава ООН.

8 Статья 22 Договоренности о правилах и процедурах, регулирующих разрешение споров.
} 
после кризисных периодов. Так, Постоянная Палата Международного Правосудия была образована после Первой мировой войны, Международный суд - после Второй мировой войны, Орган по разрешению споров ВТО - после сложнейшего периода в истории международных торговых отношений, который предшествовал созданию Всемирной торговой организации. Это, очевидно, указывает на то, что на органы международного правосудия (особенно на органы международного судопроизводства) возлагаются надежды по поддержанию стабильности международных отношений посредством мирного урегулирования международных споров в той мере, в какой эта цель может быть достигнута посредством права.

Заслуживает внимания тот факт, что инициатива создания органа международного правосудия еще в конце XIX века принадлежала дореволюционной России. Именно предложения российского правительства, включающие создание международного третейского суда, легли в основу программы работы Гаагской мирной конференции, состоявшейся в 1899 году. К сожалению, ни Советский Союз, ни Российская Федерация впоследствии не участвовали в Международном суде в качестве сторон спора, хотя в разные годы судьями Международного суда являлись советские (российские) юристы. Однако СССР и РФ принимали участие в выработке консультативных заключений Международного суда, что свидетельствует о том, что Россия признает высокий статус консультативных заключений и то влияние, которое они оказывают на развитие международных отношений и международного права. Поскольку руководство Российской Федерации неоднократно подчеркивало недопустимость односторонних действий и важность урегулировании любых международных конфликтов только мирными средствами, можно ожидать, что позиция России в вопросе более активного и полного участия в деятельности Международного суда может измениться.

Причины увеличения числа органов международного правосудия. В эпоху глобализации происходит существенное увеличение сделок с международным элементом, а также интенсификация международных связей в таких областях, как торговля, образование, охрана окружающей среды, транспорт, высокие технологии, строительство международных газопроводов, совместное освоение природных ресурсов и т.д. Это ведет к тому, что международные организации и частные лица все больше становятся вовлеченными в международную жизнь. 
Во всех указанных случаях субъекты соответствующих правоотношений взаимодействуют на основе норм и принципов международного права, и, как следствие, между ними все чаще возникают споры, требующие эффективного урегулирования. Обращение в существующие органы международного правосудия либо оказывается невозможным по причине отсутствия у одной из сторон процессуальной правоспособности, либо разбирательство в таком органе занимает слишком много времени, либо возникшие разногласия могут быть эффективно урегулированы только в рамках специализированного органа международного правосудия.

Органы международного правосудия создаются между государствами, объединенными общими интересами и целями. Порой это связано с желанием ограничить доступ третьих лиц в соответствующий орган международного правосудия, чтобы осуществлять определенный контроль над его деятельностью и т.д. Это, в частности, касается случаев создания органов международного правосудия в рамках региональных интеграционных объединений.

Никто не может навязать государству юрисдикцию того или иного органа международного правосудия против его воли. В то же время, когда государства создают органы международного правосудия, это значит, что они стремятся урегулировать будущие разногласия в соответствии с нормами международного права и принципами мирного урегулирования международных споров. Поэтому тенденцию увеличения числа органов международного правосудия можно только приветствовать.

Плюсы увеличения числа органов международного правосудия. Положительного в создании новых, специализированных органов международного правосудия множество.

Прежде всего следует заметить, что неурегулированные либо потенциальные споры вносят напряженность в международное общение, создают угрозу международному миру и безопасности. Поэтому расширение возможностей по обращению и урегулированию разногласий в органах международного правосудия способствует реализации фундаментального принципа международного права - мирного урегулирования международных споров.

Одновременно деятельность органов международного правосудия способствует повышению роли международного права в регулировании многообразных международных связей, укреплению доверия к нему со стороны членов международного сообщества, а также способствует 
лучшему пониманию норм и принципов международного права. Кроме этого наличие большого числа органов международного правосудия указывает на «зрелость» отрасли международного права.

Многие международные споры, за исключением, пожалуй, территориальных споров, в той или иной степени затрагивают интересы частных лиц. Например, во всех без исключения спорах, рассматриваемых в рамках ВТО, бенефициарами преимуществ, предоставленных членами ВТО в ходе многосторонних торговых переговоров, являются именно частные лица. Несмотря на то что последние не имеют права прямого доступа в ОРС, частные лица вправе предоставлять третейским группам и Апелляционному органу информацию amicus curie, которая может оказывать существенное влияние на разбирательство соответствующего спора ${ }^{9}$. Частные лица имеют право доступа в Европейский суд по правам человека, в Международный центр по урегулированию инвестиционных споров и др. Увеличение числа органов международного правосудия способствует вовлечению частных лиц в процедуру международного судопроизводства. Очевидно, что большинство будущих органов международного правосудия в той или иной степени будут предусматривать право частных лиц на участие в разбирательствах.

Многие органы международного правосудия, обладающие обязательной юрисдикцией, являются частью определенных договорных режимов. Возможность оспаривания в судебном порядке мер, принятых в нарушение взятых на себя международных обязательств, служит хорошим стимулом для урегулирования возникающих разногласий в процессе переговоров. Например, в рамках ВТО подавляющее большинство торговых конфликтов разрешается на стадии консультаций, без обращения в Орган по разрешению споров.

Также характерно, что в эпоху глобализации происходит интенсификация международных связей не только в областях, имеющих общечеловеческое значение, но и в достаточно узких сферах. Урегулирование споров, вытекающих из таких областей (как правило, автономных режимов) требует специальных познаний. Если представить, что такие споры могли бы разрешаться исключительно в рамках универсальных органов международного правосудия, то это значит, что состав судей, рассматривающих соответствующий спор, должен

9 CM.: European Communities - Measures Affecting Asbestos and Asbestos-Containing Products, AB-2000-11 WT/DS135/AB/R. 
был бы формироваться ad hoc, в зависимости от их специализации. Однако для обеспечения стабильности международно-правовой системы и предсказуемости разрешения споров крайне важно рассмотрение споров постоянно действующими органами правосудия, что среди прочего предполагает относительно постоянный состав судей. Противники создания специализированных судов могут возразить, что узкая специализация судей отнюдь не будет способствовать эффективному разрешению споров. Однако это опасение лишено оснований, потому что при рассмотрении подавляющего большинства международных споров судьям и арбитрам приходится анализировать в числе прочих и вопросы общего международного права ${ }^{10}$.

Более того, арбитры, назначаемые $a d$ hoc, при принятии решений в большинстве случаев не считают необходимым учитывать предыдущую практику разрешения аналогичных споров. Они, как правило, не заглядывают в будущее, пытаясь определить, к каким последствиям для международного сообщества приведет принятие ими того или иного решения, в то время как судьи постоянных органов международного правосудия (особенно органов судопроизводства) при рассмотрении любого спора в обязательном порядке обращаются к предыдущей практике, что способствует предсказуемости разрешаемых споров и, следовательно, стабильности международно-правовой системы.

Немаловажным фактом является также то, что международными судьями и арбитрами, как правило, назначаются лица высочайшей квалификации, специализирующиеся в соответствующих областях международного права. Например, Апелляционный орган ВТО «состоит из лиц, обладающих признанным авторитетом, которые доказали свою компетентность в области права, международной торговли и в общих вопросах, входящих в сферу охваченных соглашений» ${ }^{11}$. Поэтому увеличение числа органов международного правосудия способствует уяснению содержания международного права ввиду того, что нормы и принципы международного права все чаще становятся предметом рассмотрения высококвалифицированными, авторитетными судьями. При этом решения и доклады органов международного правосудия могут

${ }_{10}$ CM.: United States - Standards for Reformulated and Conventional Gasoline. WT/DS2/ AB/R, 20 May 1996, p. 16; Korea - Measures Affecting Governmental Procurement. WT/ DS163/R, 19 January 2000, p. 7.96.

11 Пункт 3 ст. 17 Договоренности и правилах и процедурах, регулирующих разрешений споров. 
включать доказательства существования обычноправовых норм 12 . Это не означает, что международные судьи и арбитры не принимают ошибочных решений. Тем не менее есть все основания полагать, что в области международного публичного права случаи судебных ошибок встречаются гораздо реже, чем при разрешении споров национальными судами.

И, наконец, самое главное. Большинство решений органов международного правосудия являются не просто решениями, разрешающими конфликт между спорящими сторонами. Решения органов международного правосудия, особенно решения органов международного судопроизводства, напрямую влияют на ожидания и поведение субъектов международного права, а также оказывают существенное влияние на развитие международного публичного права.

Органы международного правосудия не только вносят вклад в мирное урегулирование международных споров. Важнейшим преимуществом наличия большого числа органов международного правосудия является то, что они способствуют развитию международного права. Многие идеи, высказываемые судьями и арбитрами таких органов, особенно по узкоспециализированным вопросам, заслуживают того, чтобы со временем быть инкорпорированными в саму систему международного права.

Обеспечение единства системы органов международного правосудия при отсутствии между ними формальных связей. В одном из своих выступлений перед Комиссией по международному праву ООН Председатель Международного суда судья Гийом Гилберт (Guillaume Gilbert) выразил опасение, что непоследовательность в урегулировании споров различными органами международного правосудия может нарушить единство международного права. В частности, судья Г. Гилберт указал на такие проблемы, как возможности выбора удобного суда, а также принятие противоречащих друг другу решений при применении одних и тех же правовых норм. По мнению Г. Гилберта, указанные проблемы могут быть решены путем наделения Международного суда полномочиями по пересмотру решений других судов, хотя эта цель труднодостижима, поскольку она требует политической воли ${ }^{13}$.

12 Jonathan I. Charney, Comment: The Implications of Expanding International Dispute Settlement Systems: The 1982 Convention on the Law of the Sea, 90 AM. J. INT'L L. 69. Pages 69-75, (1996). P. 74.

13 Sixth Committee - 1a - Press Release GA/L/3157 17th Meeting (AM) 27 October 2000. 
Однако представляется, что создание иерархии в системе органов международного правосудия, во главе которой будет стоять Международный суд, не только невозможно, но и вредно. В системе международного права не может быть единого органа, мнение которого было бы определяющим во всех вопросах, пусть даже таким органом является Международный суд. Кроме того, ни Устав ООН, ни Статут Международного суда не предусматривают каких-либо ограничений в отношении права членов организации по созданию органов международного правосудия. Помимо прочего, наделение Международного суда статусом Высшего суда в области международного права автоматически лишит остальные органы международного правосудия всех преимуществ, благодаря которым они, в принципе, были созданы.

Учреждение новых органов международного правосудия, не угрожает единству системы международного права. Объединяющим фактором для всех органов международного правосудия является, во-первых, то, что все они разрешают споры на основании международного права, и, во-вторых, все они признают ведущую роль Международного суда.

Специализированные органы международного правосудия, как правило, рассматривают споры, вытекающие из определенных договорных режимов. Международный суд был и остается самым авторитетным органом международного правосудия. Решения и консультативные заключения Суда, особенно в области обычного международного права, оказывают большое влияние на развитие права. Анализ практики разрешения споров различными органами международного правосудия показывает, что, несмотря на то что в отдельных вопросах точки зрения судей и арбитров могут не совпадать, в вопросах, имеющих основополагающее для международного права значение, высказывается практически без исключения полное единодушие. Органы международного правосудия не могут не принимать во внимание мнение Суда по тем или иным вопросам. Более того, они периодически ссылаются даже на решения Постоянной Палаты Международного Правосудия.

В настоящее время количество споров, находящихся на рассмотрении Международного суда, достаточно велико. Это говорит о том, что, несмотря на наличие множества альтернативных органов правосудия, Международный суд остается наиболее авторитетным органом правосудия. Суд рассматривает споры особой важности, имеющие существенное значение для поддержания международного мира и безопасности. 
И ничто не указывает на то, что ситуация может измениться. Даже длительность процедуры рассмотрения споров в рамках Международного суда не следует рассматривать в качестве фактора, препятствующего эффективной деятельности Суда. Ускорение процедуры разрешения споров в рамках Международного суда, вероятнее всего, не будет способствовать увеличению числа рассматриваемых споров. Это связано в первую очередь с тем, что, когда государства выражают согласие на рассмотрение соответствующего спора Международным судом, это указывает и на особую важность данного вопроса. Следовательно, принципиально важно, чтобы все аргументы спорящих сторон были тщательнейшим образом проанализированы и чтобы у участвующих в процедуре государств были широкие возможности по отстаиванию своих интересов. Именно поэтому существующая процедура, включая временные рамки рассмотрения споров, полностью соответствует задачам, возложенным на Международный суд членами международного сообщества.

Представляется, что авторитет решений Международного суда может еще более повыситься, если при рассмотрении споров Суд будет принимать во внимание решения других органов международного правосудия. Причем в отдельных случаях Суд мог бы принимать такие решения во внимание в соответствии с п. «d» ст. 38 Статута. И наоборот, в случае если, по мнению Суда, тот или иной орган международного правосудия принял ошибочное решение либо методы толкования норм международного права иными органами международного правосудия представляются ошибочными, целесообразно, чтобы Суд, рассматривая спор, затрагивающий аналогичные нормы права, указал на некорректность такого толкования либо сделанных выводов. В таком случае крайне велика вероятность того, что орган международного правосудия при рассмотрении последующих споров будет придерживаться позиции Международного суда. В противном случае его решение не будет авторитетным. А авторитетность и убедительность решений - это важнейшие факторы, от которых напрямую зависит эффективность деятельности органов международного правосудия.

Это, конечно же, не значит, что позиция Международного суда всегда должна учитываться другими органами международного правосудия. В противном случае это сделало бы невозможным развитие международного права. Основополагающей задачей любого органа международного правосудия является урегулирование переданного 
на его рассмотрение спора. Разбирательство должно быть объективным и беспристрастным, а судьи и арбитры должны обладать полной свободой по принятию тех решений, которые они считают в наилучшей степени отвечающими требованиям права.

Теоретически существует риск того, что специализированные органы международного правосудия могут принимать противоречащие друг другу решения. Однако этот риск невелик. Как уже было отмечено, специализированные органы международного правосудия, как правило, создаются в рамках различных договорных режимов, т.е. юрисдикция таких органов правосудия ограничена вопросами, вытекающими из определенных соглашений.

Что касается конфликта решений по вопросам общего международного права либо по вопросам, вытекающим из универсальных договоров и конвенций, то в этих областях безусловным авторитетом обладают только решения Международного суда. Принципиально важно, чтобы судьи и арбитры специализированных органов международного правосудия не возлагали на себя функций по авторитетному толкованию норм общего международного права, поскольку эта функция, безусловно, принадлежит Международному суду. Поэтому в случае, когда специализированным органам международного правосудия необходимо разрешить вопрос из области общего международного права, им следует, руководствуясь принципом экономичности судебного рассмотрения, сослаться на соответствующее мнение Международного суда.

Хотя de јure решения Международного суда обладают такой же юридической силой, что и обязательные для спорящих сторон решения любого другого органа международного правосудия, de facto Международный суд имеет статус primus inter pares. Поэтому Международный суд мог бы взять на себя функцию по выработке принципов международного судопроизводства, включая принципы взаимодействия между судьями и арбитрами различных органов международного правосудия. Было бы также целесообразным привлечение к этой работе судей и арбитров других органов международного правосудия. Указанные принципы должны отражать консолидированную позицию международного судейского сообщества, так как чем шире будет консенсус, тем выше будет авторитет таких рекомендаций, которые, не исключено, со временем могут стать обычными нормами международного права. 


\section{Proliferation of International Judicial Bodies and their Impact on International Law System (Summary)}

\section{Anait S. Smbatyan*}

Today's international legal landscape is different from that which was in existence 10 years ago. The International Court of Justice is no longer the only permanent international court. Many other specialized and regional international judicial bodies have been established, such as the International Tribunal for the Law of the Sea, Dispute Settlement Body of the World Trade Organization, the ad hoc International Criminal Tribunals for the Former Yugoslavia and Rwanda and etc. This is undoubtedly very good news for international law system, because the proliferation of international judicial bodies signals an increase in international litigation and has very positive impact on development of international law.

The establishment of a hierarchy of international judicial bodies is extremely difficult and will have a very negative impact on specialized international judicial bodies. The risk of fragmentation of international law because of conflicting judgments and/or conflicting interpretation of the same norms is insignificant. The International Court of Justice remains the only international court of general jurisdiction. Its pronouncements on general international law are the most persuasive for all the specialized international judicial bodies, which contribute to the development of international law in specialized areas. So, the unity of international law system is maintained.

\footnotetext{
*Anait S. Smbatyan - Ph.D. in Law, lecturer at the Chair of Public law of the Russian Foreign Trade Academy; deputy head of the department of contractual and international corporate affairs of the OAO «Mechel».
} 